\title{
EFFECT OF POLYPROPYLENE FIBER REINFORCED ON PROPERTIES OF CONCRETE
}

\author{
Salahaldein Alsadey* \\ Department of Civil Engineering, Bani Walid University, Libya. salahalsadey@yahoo.com
}

*Corresponding Author: -

Email: salahalsadey@yahoo.com

\begin{abstract}
: -
This paper investigates on analyzing the effects of use of Polypropylene fiber in the mechanical properties of concrete. One of the main tasks of the construction industry is to increase the strength and reliability of structures while reducing construction costs. Effective use of fiber reinforced concrete is likely to lead to reduction in reinforcement. Three mixes used polypropylene fiber with content $1.0 \%, 1.5 \%$, and $2.0 \%$ percent. To provide a basis for comparison, reference specimens were cast without polypropylene fiber. The test results showed that the increase of mechanical properties (compressive strength) resulting from added of polypropylene fiber was relatively high.
\end{abstract}

Keywords: - polypropylene fiber, strength of concrete, fiber reinforced concrete.

\section{(c) $(\$)$}




\section{INTRODUCTION}

Concrete is the most widely used construction material has several desirable properties like high compressive strength, stiffness and durability under usual environmental factors. At the same time concrete is brittle and weak in tension. Plain concrete has two deficiencies, low tensile strength and a low strain at fracture. These shortcomings are generally overcome by reinforcing concrete. Normally reinforcement consists of continuous deformed steel bars or pre-stressing tendons. The advantage of reinforcing and pre-stressing technology utilizing steel reinforcement as high tensile steel wires have helped in overcoming the incapacity of concrete in tension but the ductility magnitude of compressive strength.

Fibre reinforced concrete (FRC) is Portland cement concrete reinforced with more or less randomly distributed fibres. In FRC, thousands of small fibres are dispersed and distributed randomly in the concrete during mixing, and thus improve concrete properties in all directions.

Fibre reinforced concrete is cement- based composite material that has been developed in recent years. It has been successfully used in construction with its excellent flexural-tensile strength, resistance to spitting, impact resistance and excellent permeability and frost resistance. It is an effective way to increase toughness, shock resistance and resistance to plastic shrinkage cracking of the mortar. Fibre is a small piece of reinforcing material possessing certain characteristics properties. They can be circular, triangular or flat in cross-section. The fire is often described by a convenient parameter called "aspect ratio". The aspect ratio of the fibre is the ratio of its length to its diameter. The principle reason for incorporating fibres into a cement matrix is to increase the toughness and tensile strength and improve the cracking deformation characteristics of the resultant composite. For fibre reinforced concrete to be a viable construction material, it must be able to compete economically with existing reinforcing system.

Polypropylene fibres are one of the main types of fibre used in the market, apart from steel fibres. However, both types of fibres vary significantly in their elastic and strength properties. For 40 years, steel fibres have been commonly used in concrete flatwork and sprayed concrete applications. The emergence of polypropylene fibres has introduced to the world the possibility of having a high-performance and more cost-effective product in the market place. Polypropylene fibres also possess better durability as plastic does not rust. It also contributes to the ease in handling as it weight about one-fifth of an equivalent steel fibre.

According to Rana, 2013 fiber-reinforced concrete is becoming an increasingly popular construction material due to its improved mechanical properties over unreinforced concrete and its ability to enhance the mechanical performance of conventionally reinforced concrete. Fiber reinforcement is one of the most important modification methods to alter the brittle nature of plain concrete. Fibers are generally used as resistance of cracking and strengthening of concrete.

\section{A Use of fibers in concrete}

Fibers are usually used in concrete for the following reasons:

i. To control cracking due to both plastic shrinkage and drying shrinkage.

ii. They also reduce the permeability of concrete and thus reduce bleeding of water.

\section{Aim of Study}

The aim of this investigation is to study the effect of polypropylene fiber on the compressive strength of normal concrete.

\section{Materials and Experimental Details}

The experimental investigation was carried out in the Construction Materials Laboratory of the Faculty of Engineering at Bani Walid University Libya. Concrete mixes containing ordinary Portland cement, sea sand, crushed coarse aggregate, water, and different percentage of polypropylene fiber content were studied. The used ordinary Portland cement satisfies the ASTM requirements. Locally sea sand was used, which had specific gravity of 2.66 and its grading fell within ASTM. Crushed coarse aggregate had specific gravity of 2.70. The sieve analysis of coarse aggregate is carried out according to ASTM. The fibrillated polypropylene fiber was used; the properties of this fiber are illustrated in Table (1). Three identical concrete mixes having different percentage of fiber content were used in this investigation. The same mix, which is obtained according to BS, was used through the all investigation. The water cement ratio (W/C) was $06 \%$.

\section{TABLE 1 PROPERTY OF POLYPROPYLENE FIBRE}

\begin{tabular}{|c|c|c|}
\hline No & Property & Description \\
\hline 1 & Colour & Natural \\
\hline 2 & Design & Monofilament Fiber \\
\hline 3 & Fibre Length & $18 \mathrm{~mm}$ \\
\hline 4 & Diameter & 18 -micron nominal \\
\hline 5 & Density & 0.91 gm nominal \\
\hline 6 & Absorption & Nil \\
\hline 7 & Specific Surface Area & 250 sq meters per KG \\
\hline 8 & Melt Point & $160^{\circ} \mathrm{C}$ \\
\hline 9 & Ignition Point & $365^{\circ} \mathrm{C}$ \\
\hline 10 & Thermal Conductivity & Low \\
\hline 11 & Electrical Conductivity & Low \\
\hline 12 & Acid Resistance & High \\
\hline 13 & Alkali Resistance & $100 \%$ \\
\hline
\end{tabular}




\section{Preparation of test specimens}

Aggregate and cement were first mixed, and water was progressively added until a homogeneous concrete was obtained. Then, the fibers were added, and concrete was mixed for at least 3 minutes in order to allow a sufficient time for fiber even distribution in the mixture. For each mixture three concrete cubes with dimensions of 150x $150 \times 150 \mathrm{~mm}$ were cast into molds consolidated by steel bar to decrease the amount of air bubbles. The specimens were remodeled after 24 hour and then placed in curing tank under laboratory conditions for 28 days for compressive concrete strength at age 28 days for compressive strength of concrete.

\section{Results and Discussion}

\section{Fresh Properties}

The test results are shown in Table 2 for the fresh concrete test conducted clearly indicates the difference of each test in assessing the workability of freshly mixed fibre reinforced concrete. For the assessment of workability, slump test and flow table test were adopted in the study. However, the line graph below shows the results for the slump tests conducted on polypropylene fibres of different percentage of fibres. Slump values decrease when addition different percentages of polypropylene fibres it means require superplasticisers to achieve better workability.

TABLE 2 RESULTS OBTAINED FROM SLUMP AND FLOW TEST

\begin{tabular}{|c|c|c|c|}
\hline Mixture & $\begin{array}{l}\text { Fiber content } \\
\text { \% }\end{array}$ & $\begin{array}{c}\text { Slump } \\
(\mathbf{m m})\end{array}$ & Flow (mm) \\
\hline M1 & 0 & 130 & 510 \\
\hline M2 & 1.0 & 50 & 480 \\
\hline M3 & 1.5 & 20 & 450 \\
\hline M4 & 2.0 & 10 & 430 \\
\hline
\end{tabular}
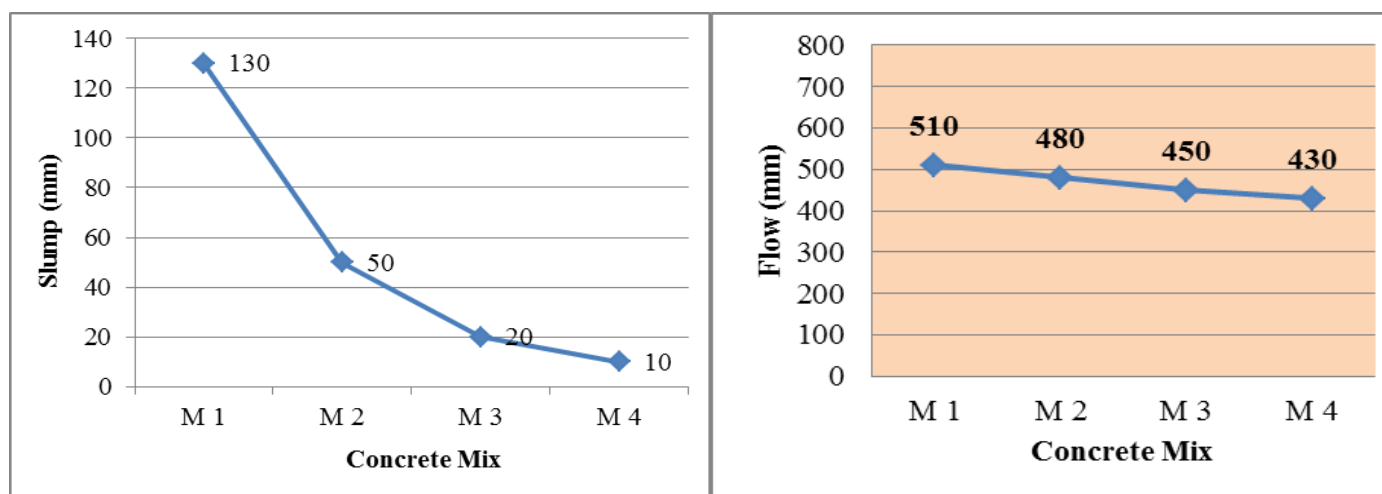

Fig 1. Line chart showing results of Slump and Flow Test

\section{A. Compressive Strength}

Compressive strength values obtained after 28 days are summarized in Figure 2 shows that the 28 days compressive strength for fibrous concrete increase from $26 \mathrm{~N} / \mathrm{mm}^{2}$ for $0.0 \%$ fiber volume content to $29.40,29.50$, and $24.43 \mathrm{~N} / \mathrm{mm}^{2}$ for $1.0 \%, 1.5 \%$, and $2.0 \%$ fiber volume contents, respectively. That is shown increase in the compressive strengths for fibrous concrete compared to non-fiberous concrete. Generally, the compressive strength for polypropylene fibre is slightly higher compare to non-fibre concrete. This behaviour is also noted by previous studies. From the compressive strength test results, the compressive strength of concrete was predicted in term of fiber content.

TABLE 3 RESULTS OBTAINED FROM COMPRESSION STRENGTH TEST AFTER 28 DAYS

\begin{tabular}{|c|c|c|}
\hline Mixture & Fiber Content \% & $\begin{array}{c}\text { Compressive Strength } \\
\left(\mathrm{N} / \mathrm{mm}^{2}\right)\end{array}$ \\
\hline M1 & 0 & 26.00 \\
\hline M2 & 1.0 & 29.40 \\
\hline M3 & 1.5 & 29.50 \\
\hline M4 & 2.0 & 24.43 \\
\hline
\end{tabular}




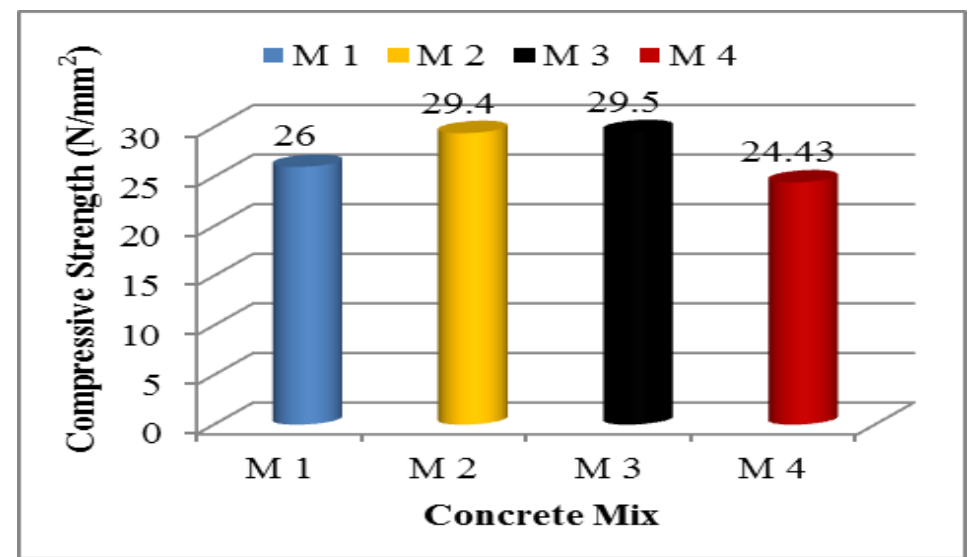

Fig 2. Line chart showing results of Compressive Strength Test

\section{Conclusion}

The aim of the study was met as it had successfully investigated and analysed the effects polypropylene fibers can be still promising as polypropylene fibers reinforced concrete is used for sustainable and long-lasting concrete structures. polypropylene fibers are widely used as a fiber reinforced concrete all over the world. Lot of research work had been done on polypropylene fiber reinforced concrete and lot of researchers work prominently over it. The polypropylene fibers are mostly used fiber for fiber reinforced concrete out of available fibers in market. According to many researchers, the addition of polypropylene fiber into concrete creates low workable or inadequate workability to the concrete.

An effort was made to study the effect of use of fiber in high strength concrete and draw a conclusion with respect to an optimum mix with the balance between the cost and the advantage it offers with respect to the mechanical properties. The general perception of fiber hindering the flowability of concrete was discussed in detail with the industry experts and also observed during the conduct of field trails. However, the slump test should not be considered as a satisfying test to determine the workability of the concrete. This is due to the stiffening effects of the fibres. The slump results will not show the actual workability of the concrete. It was inferred that the problem of hinderence in flowability can be neutralized through nominal enhanced dosage of superplasticizer without compromising on other properties. This will enable a flowable concrete with fiber thereby increasing the compression test results indicated that, generally, the compressive strengths for polypropylene fibre reinforced concrete increases with the addition of polypropylene fibre reinforced concrete without any addition of admixtures in amount of $1 \%$ and $1.5 \%$.

\section{Acknowledgement}

The author would like to express gratitude to the students of Civil Engineering for their continuous support during experimental work.

\section{References}

[1].Amit Rana (2013) “Some Studies on Steel Fiber Reinforced Concrete”. International Journal of Emerging Technology and Advanced Engineering.

[2].ACI 544.1R (1996). State-of-the-Art Report on Fiber Reinforced Concrete, American Concrete Institute, Farmington Hills, Michigan.

[3].ACI Committee 544. 1982. State-of-the-Report on Fibre Reinforced Concrete, (ACI 544.1R-82), Concrete International: Design and Construction. 4(5): 9-30, American Concrete Institute, Detroit, Michigan, USA.

[4].ACI Committee 544. 1989. Measurement of Properties of Fibre Reinforced Concrete, (ACI 544.2R-889).

[5].ASTM C 192/C 192M. 2002. - Standard Practice for Making and Curing Concrete Test Specimens in the Laboratoryll. ASTM International.

[6].British Standard Institution, BS 1881: Part 102 (1983). "Methods for Determination of Slump".

[7].British Standard Institution, BS 1881: Part 116 (1983). "Methods for Determination of Compressive Strength of Concrete Cube". 